\title{
Transfer of Veillonella Prévot and Acidaminococcus Rogosa from Neisseriaceae to Veillonellaceae fam. nov., and the Inclusion of Megasphaera Rogosa in Veillonellaceae
}

\author{
MORRISON ROGOSA \\ Laboratory of Microbiology and Immunology, National Institute of \\ Dental Research, National Institutes of Health, Bethesda, \\ Maryland 20014
}

\begin{abstract}
Veillonellaceae (order Eubacteriales) is proposed as the name of a new family to include three genera of presently known, anaerobic, gram-negative, coccal bacteria. It is herein proposed that Veillonella Prévot 1933 and Acidaminococcus Rogosa 1969 be transferred from Neisseriaceae and be included together with Megasphaera Rogosa 1971 in Veillonellaceae fam. nov. The type genus is Veillonella Prévot.
\end{abstract}

Presently the family Neisseriaceae contains genera which have contrasting characteristics. There are genera whose organisms are either aerobic or anaerobic and exhibit great differences in terminal-respiration mechanisms, biochemical pathways, attack on substrates, and genetic makeup. In order to group similar organisms together, it is here proposed that Veillonella Prévot 1933 and Acidaminococcus Rogosa 1969 be transferred from Neisseriaceae Prévot 1933 to Veillonellaceae fam. nov. It is also proposed that the recently described and named genus Megasphaera Rogosa 1971 be placed in Veillonellaceae. This arrangement takes advantage of the remarkable general scientific progress since 1933 and effects a more reasonable placement of the gramnegative, aerobic cocci in Neisseriaceae and of the gram-negative, anaerobic cocci in Veillonellaceae.

The family Neisseriaceae was named by Prévot (9) on p. 100 as Neisseriacées (nouv. fam.) and was described on p. 119 as follows:

"Position dans la systématique.-Avec le genre Neisseria TREVISAN, il [Veillonella] forme la nouvelle famille des Neisseriacées, ou Cocci Gram-négatifs, que nous subdivision en deux tribus:

Neisseriacées (n. fam.) Neisseriées: genre unique Neisseria. Veillonellées: genre unique Veillonella."

This is the extent of the description of the family Neisseriaceae, although from the context it is clear that one of the genera in this family,
Veillonella, is anaerobic. Although Neisseriaceae was revised by Murray and Branham (8) and by Branham, Pelczar, and Murray (3) who added some detail, Veillonella has remained in the family Neisseriaceae since the original Prévot publication in 1933.

Besides Veillonella, other recently studied gram-negative cocci such as Acidaminococcus (12) and Megasphaera (13) present a problem because they, too, are anaerobic. Previously, Acidaminococcus had been placed in Neisseriaceae by Rogosa (12). Megasphaera has not yet been allocated to any family (13).

Recently Catlin (4) ably summarized the genetic and other evidence showing the distinctness of Neisseria catarrhalis from the type species and other species of Neisseria and proposed the transfer of $N$. catarrhalis to a new genus, Branhamella (type species: Branhamella catarrhalis within Neisseriaceae). The so-called "false neisserias" (branhamellas and acinetobacters) and/or "moraxellas" historically have been in a confused status; very similar organisms have been given names spreading through diverse genera and families $(1,2,18)$. Baumann et al. $(1,2)$ have comprehensively studied and described such organisms under the names Moraxella (for the oxidase-positive strains) and Acinetobacter (for the oxidasenegative strains). However, they were not concerned with the position of these genera in higher taxa such as families, and they offered no discussion or opinions in this regard.

There seems to be some agreement $(1,18)$ 


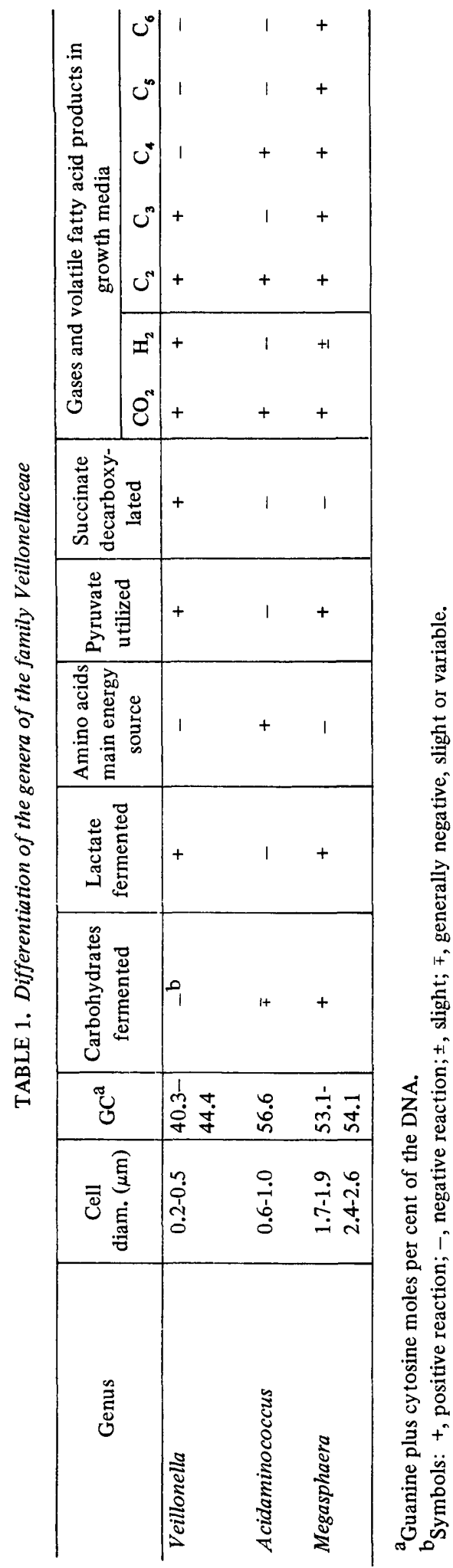

on Moraxella as the generic name for certain oxidase-positive, short, plump diplobacilli or coccobacilli and on Acinetobacter (2) [synonym: Lingelsheimia (18)] for the oxidasenegative organisms. A family Moraxellaceae Ryter and Piéchaud 1963 has been proposed (17) to include Moraxella and Acinetobacter. However, if rods and cocci could be included in one family as in Lactobacillaceae, for example, there is probably no formal reason why Moraxella and Acinetobacter could not be included in Neisseriaceae, provided this family is appropriately redefined. This would at least have the virtue of gathering together four genera with aerobic metabolism, namely, Neisseria, Branhamella, Moraxella, and Acinetobacter. This arrangement is consistent with the recent recommendation of the Subcommittee on the Taxonomy of Moraxella and Allied Bacteria of the International Committee on Nomenclature of Bacteria (7).

Enormous unresolved nomenclatural problems obviously exist. It is not my purpose to wander further in this thicket of problems where international experts have been unable to agree among themselves. However, it does not seem wise to include genera like Neisseria, Branhamella, Veillonella, and Acidaminococcus, with such divergent aerobic and anaerobic metabolisms, in a single family.

Therefore, it is proposed that the genera Veillonella Prévot 1933 and Acidaminococcus Rogosa 1969, the latter having been placed in Neisseriaceae by Rogosa (12), be transferred to Veillonellaceae fam. nov. This family also includes the genus Megasphaera Rogosa 1971. A description of this new family, which is placed in the order Eubacteriales, follows.

\section{Veillonellaceae fam. nov.}

Veil.lo.nel.la'ce.ae. M.L. fem. n. Veillonella type genus of the family;-aceae ending to denote a family; M.L. fem.pl.n. Veillonellaceae the Veillonella family.

Cocci, varying in diameter from small (ca. 0.3 to $0.5 \mu \mathrm{m})$ to large $(c a . .2 .5 \mu \mathrm{m})$; occur characteristically in pairs; single cells, masses, or chains may also occur, although the chains may show gaps, illustrating the basic diplococcal arrangement. Adjacent sides of cell pairs may be flattened. No endospores. Nonmotile; no flagella. Gram-negative but may have tendency to resist decolorization. Anaerobic. Cytochrome oxidase negative. Catalase negative, but some strains decompose peroxide by means of a pseudocatalase (nonheme containing). Chemoorganotrophic. Possess complex nutritional requirements. Gas is produced, frequently abun- 
dantly, in culture. Carbohydrates may or may not be fermented. Lactic acid may not be produced and if present is not a major product; lactate is fermented by some genera with the production of $\mathrm{CO}_{2}, \mathrm{H}_{2}$, and various lower volatile fatty acids containing 2 to $6 \mathrm{C}$ atoms.

Parasites of homothermic animals such as man, ruminants, rodents, and pigs, particularly found in the alimentary tract.

The type genus is Veillonella Prévot 1933.

The genera of Veillonellaceae are:

1. Veillonella Prévot, 1933.

Type species: V. parvula (Veillon and Zuber, 1898) Prévot, 1933.

Objective synonym: Staphylococcus parvulus Veillon and Zuber, 1898, 542.

Descriptions of genus, type species, and serotype strains were corrected and up-dated by Rogosa [11, 14-16 (see especially reference 11)].

2. Acidaminococcus Rogosa, 1969.

Type species: $A$. fermentans Rogosa 1969. Descriptions of genus, type species, and type strain by Rogosa (12).

3. Megasphaera Rogosa, 1971.

Type species: $M$. elsdenii Rogosa 1971.

Synonyms: Organism LC of Elsden et al. 1956. Peptostreptococcus elsdenii Gutierrez et al. 1959.

Descriptions of genus, type species, and type strain up-dated by Rogosa (13).

\section{LITERATURE CITED}

1. Baumann P., M. Doudoroff, and R. Y. Stanier. 1968. Study of the Moraxella group. I. Genus Moraxella and the Neisseria catarrhalis group. J. Bacteriol. 95:58-73.

2. Baumann, P., M. Doudoroff, and R. Y. Stanier. 1968. A study of the Moraxella group. II. Oxidase-negative species (Acinetobacter). J. Bacteriol. 95:1520-1541.

3. Branham, S. E., M. J. Pelczar, and E. G. D. Murray. 1957. In Bergey's manual of determinative bacteriology, 7 th ed., p. $480-481$. Williams \& Wilkins Co., Baltimore.

4. Catlin, B. W. 1970. Transfer of the organism named Neisseria catarrhalis to Branhamella gen. nov. Int. J. Syst. Bacteriol. 20:155-159.

5. Elsden, S. R., B. E. Volcani, F. M. C. Gilchrist, and D. Lewis. 1956. Properties of a fatty acid forming organism isolated from the rumen of sheep. J. Bacteriol. 72:681-689.

6. Gutierrez, J., R. E. Davis, I. L. Lindahl, and E. J. Warwick. 1959. Bacterial changes in the rumen during the onset of feed-lot bloat of cattle and characteristics of Peptostreptococcus elsdenii n. sp. Appl. Microbiol. 7:16-22.

7. Lessel, E. F. (Secretary). 1971. International Committee on Nomenclature of Bacteria, Subcommittee on the Taxonomy of Moraxella and Allied Bacteria, Minutes of the Meeting. Int. J. Syst. Bacteriol. 21:213-214.

8. Murray, E. G. D., and S. E. Branham (ed.). 1948. In Bergey's manual of determinative bacteriology, 6th ed., p. 295. The Williams \& Wilkins Co., Baltimore.

9. Prévot, A. R. 1933. Études de systématique bactérienne. 1. Lois générales.-II Cocci anaérobies. Ann. Sci. Natur. Bot. 15:23-258.

10. Rogosa, M. 1964. The genus Veillonella. I. General cultural, ecological, and biochemical considerations. J. Bacteriol. 87:162-170.

11. Rogosa, M. 1965. The genus Veillonella. IV. Serological groupings, and genus and species emendations. J. Bacteriol. 90:704-709.

12. Rogosa, M. 1969. Acidaminococcus gen. n., Acidaminococcus fermentans sp. n., anaerobic gram-negative diplococci using amino acids as the sole energy source for growth. J. Bacteriol. 98:756-766.

13. Rogosa, M. 1971. Transfer of Peptostreptococcus elsdenii Guiterrex et al. to a new genus, Megasphaera [M. elsdenii (Gutierrez et al.) comb. nov.] . Int. J. Syst. Bacteriol. 21:187-189.

14. Rogosa, M., and F. S. Bishop. 1964. The genus Veillonella. II. Nutritional studies. J. Bacteriol. 87:574-580.

15. Rogosa, M., and F. S. Bishop. 1964. The genus Veillonella. III. Hydrogen sulfide production by growing cultures. J. Bacteriol. 88:37-41.

16. Rogosa, M., M. I. Krichevsky, and F. S. Bishop. 1965. Truncated glycolytic system in Veillonella. J. Bacteriol. 90:164-171.

17. Ryter, A., and M. Piéchaud. 1963. Étude de microscope électronique de quelque souches de Moraxella. Ann. Inst. Pasteur 105:1071-1079.

18. Seeliger, H. P. R., R. H. W. Schubert, and E. Schlieber. 1968. Transfer of Bacterium anitratum Schaub and Hauber 1948 to the genus Lingelsheimia gen. nov. Int. J. Syst. Bacteriol. 18:21-32.

19. Veillon, A., and M. M. Zuber. 1898. II. Recherches sur quelques microbes strictement anaérobies et leur role en pathologie. Arch. Med. Exp. 10:517-545. 